\title{
Characteristics of Severely Anemic Pregnant Women and Perinatal Outcomes in Banfora Regional Hospital, Burkina Faso: An Epidemiological Study
}

\author{
Léon G. Blaise Savadogo ${ }^{1,2 *}$, Ouédraogo Salimata ${ }^{3}$, Cécile Tamini, Maurice Kinda1, \\ Philipe Donnen 5 \\ ${ }^{1}$ Department of Epidemiology and Public Health, Child and Mother Health, Nutrition and Survival Unit, Institut \\ Supérieur des Sciences de la Santé, Université Polytechnique de Bobo Dioulasso, Bobo Dioulasso, Burkina Faso \\ ${ }^{2}$ CR2 Epidemiology-Biostatistics-Clinical Research, School of Public Health, Université Libre de Bruxelles, \\ Bruxelles, Belgique \\ ${ }^{3}$ Centre Hospitalier Régional de Banfora, Banfora, Burkina Faso \\ ${ }^{4}$ Ecole National de Santé Publique, Bobo Dioulasso, Burkina Faso \\ ${ }^{5} \mathrm{CR} 3$ Politiques et Systèmes de Santé, Santé Internationale, Ecole de Santé Publique, Université Libre de \\ Bruxelles, Bruxelles, Belgique \\ Email: "gueswende@hotmail.com
}

Received 17 February 2014; revised 11 March 2014; accepted 18 March 2014

Copyright (C) 2014 by authors and Scientific Research Publishing Inc.

This work is licensed under the Creative Commons Attribution International License (CC BY).

http://creativecommons.org/licenses/by/4.0/

(c) (i) Open Access

\section{Abstract}

Severe anemia during pregnancy remains an acute maternal health problem in low income countries and its management is a challenge. This study aimed to analyze the characteristics of hospitalized pregnant women with severe anemia and issue of the management in a regional hospital of a low income country. Material and Methods: This was a retrospective descriptive study from January 1, 2007 to December 31, 2008, at a regional hospital maternity. Data of the 283 pregnancy severe anemia cases have been analyzed using usual Pearson's Chi square test or Fisher's exact test. Results: Of the 283 women with pregnancy severe anemia, $98 \%$ were illiterate, $98 \%$ were household women; majority were in the third trimester (64\%); $41 \%$ had no previous delivery; $49 \%$ did not had antenatal care. There were no statistics association between hemoglobin values stage and gestational age, gravidity and parity. During the hospitalization, from the 283 women with pregnancy severe anemia, deliveries occurred on $22.6 \%$; abortion on $1 \%$. From the 64 deliveries, $45.3 \%$ were alive preterm birth, $20.3 \%$ preterm stillbirth, $25.0 \%$ at term birth and $9.4 \%$ at term stillbirth. Between the 45 alive babies, $91 \%$ were low birth weight. In global, from the 283 women, mortality rate was $2.8 \%$. Conclusion: Severe anemia during pregnancy re- 
sults in maternal mortality, preterm, low birth and stillbirth even between hospitalized women. As most of the pregnancy anemia risk factors are chronic poverty related factors, intervention must be focused on prevention including health pregnant women iron supplementation and adequate nutritional diet promoting at both health facilities and community level.

\section{Keywords}

Pregnancy; Severe Anemia; Regional Hospital; Burkina Faso

\section{Introduction}

Anemia due to iron and folate deficiency is one of the most frequent pregnancy's complications in poor communities. Anemia of poor women is commonly due to inadequate diets. In rural areas of developing countries, pregnancy anemia has various and combined causes: dietary iron deficiency, folate deficiency, bleeding and intestinal parasites (hookworm or other parasites), malaria and hemoglobinopathy [1] [2]. Severe anemia during pregnancy remains an acute maternal health problem in low income countries [3] [4]. Several studies showed that pregnancy severe anemia may have adverse effects on maternal health (morbidity and increased mortality) and perinatal outcomes (prematurity, spontaneous abortions, low birth weight, fetal impairment and infant deaths) [5]-[14]. Management of pregnancy severe anemia cases remains a challenge. This study aimed to analyze the characteristics of hospitalized pregnant women with severe anemia and issue of the management in a regional hospital of a low income country.

\section{Material and Methods}

\subsection{Study Design and Site}

This was a retrospective descriptive study. The study covered the period of two years, from January 1, 2007 to December 31, 2008. The study site was the maternity of Banfora regional hospital in Burkina Faso Cascades region area. At this maternity, skilled midwifes staff, leaded by a gynecologist and obstetrician medical doctor, was in charge of care providing. This study received an approval from the regional hospital medical staff and from the regional health office.

\subsection{Study Population and Sample Size}

The study has been conducted from data of hospitalized pregnant women with severe anemia. Maternal anemia was defined severe when hemoglobin $(\mathrm{Hb})$ was $<7 \mathrm{~g} / \mathrm{dl}$. During the considered period, all hospitalized pregnancy severe anemia cases were considered. A total of 4349 women have been hospitalized at the maternity from January 1, 2007 to December 31, 2008. From these admitted women, 742 anemia cases were observed; from these anemia cases, 498 were pregnancy anemia and from these pregnancy anemia cases, 283 were pregnancy severe anemia cases (56.82\%).

\subsection{Data Collection}

Trained research midwife, not included in the maternity staff, collected data on women socio-demographic (age, education, marital status, occupation, number of pregnancy, parity), antenatal visit, gestational age, admission mode, hemoglobin level, treatment, pregnancy outcome, treatment issue. Gestational age in weeks was calculated from the first day of the last menstrual period. Preterm delivery was defined as delivery before 37 completed weeks of gravidity. LBW was defined as $<2.5 \mathrm{~kg}$. Stillbirth was defined as delivery of a dead infant after 24 weeks of gestation. Data have been recorded from patient's clinical document. The instrument for individual patient data collection was a pre-tested data case form.

\subsection{Statistical Analyses}

Data of the 283 pregnancy severe anemia cases have been considered for analysis. Usual statistics methods were 
applied. We used Pearson's Chi square test or Fisher's exact test to compare proportions. Statistical significance level was 0.05 . The data were analyzed using SPSS software version 20.

\section{Results}

The median age of the pregnant women with severe anemia was 22 years with range 15 - 42 years. All cases were singleton pregnancies. Hemoglobinopathy has been identified in 05 cases. Of the 283 women with pregnancy severe anemia; $98 \%$ were illiterate, $98 \%$ were household women; majority were in the third trimester (64\%); 41\% had no previous delivery; 49\% did not had antenatal care "Table 1".

From the 283 pregnancy severe anemia, hemoglobin was 1 - 2 g/dl for 30\%, 3 - 4 d/dl for $45 \%$ and 5 - $6 \mathrm{~g} / \mathrm{dl}$ for $25 \%$.

Table 2 shows proportion of pregnant women at different stage of hemoglobin values by women demographics characteristics. For severe pregnancy anemia there were no statistics association between hemoglobin values stage and gestational age, gravidity and parity "Table 2".

Figure 1 shows proportions of women with pregnancy severe anemia receiving variety of medical treatment: $39.22 \%$ received blood transfusion; $63.25 \%$ received oral iron therapy. Parenteral iron therapy has not been used "Figure 1".

\section{Table 1. Women socio-demographics characteristics at admission to the maternity.}

\begin{tabular}{ccc}
\hline & $\mathrm{n}$ & Percentage \\
\hline Gestational age & 181 & 64 \\
T1 & 85 & 30 \\
T2 & 17 & 6 \\
T3 & 25 & 9 \\
Parity & 142 & 50 \\
$\geq 6$ & 116 & 41 \\
$0-5$ & 184 & 65 \\
0 & 99 & 35 \\
Gravidity & & 4.9 \\
$\geq 6$ & 14 & 95.1 \\
$0-5$ & 269 & 49.1 \\
Marital status & & 50.9 \\
Single & 139 & 18.4 \\
In relationship & 144 & 81.6 \\
Antenatal care & & \\
No & 52 & 98 \\
Yes & 231 & 2 \\
Referred & & \\
Not referred & 277 & 6.9 \\
Education & 6 & \\
Illiterate & & \\
Literate & & \\
\hline
\end{tabular}

Table 2. Proportion of pregnant women at different stage of hemoglobin values by personal characteristics.

\begin{tabular}{|c|c|c|c|c|c|}
\hline & \multirow[b]{2}{*}{$\mathbf{n}$} & \multicolumn{4}{|c|}{$\%$ of pregnant women by HB stage } \\
\hline & & $1-2$ g/dl & $3-4$ g/dl & $5-6 \mathrm{~g} / \mathrm{dl}$ & $\mathbf{p}$ \\
\hline \multicolumn{6}{|c|}{ Gestational age (trimester) } \\
\hline $\mathrm{T} 1$ & 85 & 18.8 & 47 & 34.2 & \\
\hline $\mathrm{T} 2$ & 17 & 41.2 & 35.2 & 23.6 & 0.10 \\
\hline T3 & 181 & 16.2 & 54.6 & 29.2 & \\
\hline \multicolumn{6}{|c|}{ Gravidity } \\
\hline $1-5$ & 236 & 30 & 46.2 & 23.8 & 0.99 \\
\hline$\geq 6$ & 47 & 28.2 & 42.3 & 30.5 & \\
\hline \multicolumn{6}{|l|}{ Parity } \\
\hline 0 & 115 & 35.6 & 44.4 & 20 & \\
\hline $1-5$ & 142 & 24.7 & 47.9 & 27.4 & 0.29 \\
\hline$\geq 6$ & 26 & 30.8 & 38.4 & 30.8 & \\
\hline
\end{tabular}




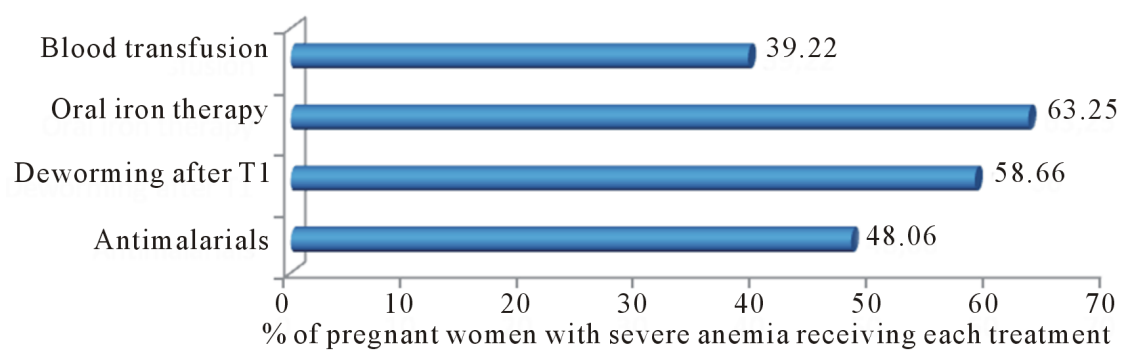

Figure 1. Percentage of pregnant women with severe anemia receiving each treatment.

During the hospitalization, from the 283 women with pregnancy severe anemia, deliveries occurred on 22.6\%; abortion on $1 \%$. From the 64 deliveries, $45.3 \%$ were alive preterm birth, $20.3 \%$ preterm stillbirth, $25.0 \%$ at term birth and 9.4\% at term stillbirth. Between the 45 alive babies, 91\% were low birth weight.

From the 111 women with pregnancy severe anemia who received blood transfusion, 20.72\% received $500 \mathrm{ml}$, $67.57 \%$ received $1000 \mathrm{ml}$ and $11.71 \%$ received $\geq 1500 \mathrm{ml}$.

In global, from the 283 women, mortality rate was $2.8 \%$, 39.9\% having been transferred from the regional hospital to a university teaching hospital, and other went out to their household. Maternal death occurred due to obstetric directs causes (Hemorrhage, eclampsia) and indirect cause (anemia).

\section{Discussion}

In our analysis, severe anemia during pregnancy resulted to maternal mortality and fetal adverse effects (45.3\% were alive preterm birth, $20.3 \%$ preterm stillbirth, $25.0 \%$ at term birth and $9.4 \%$ at term stillbirth; and from alive babies, 91\% were low birth weight). Several studies reported these consequences [8] [13] [15].

There is no evidence that pregnancy severe anemia can be reversed. Iron supplementation controlled trials during pregnancy have demonstrated consistently positive effect on maternal iron status, but no evidence on reduction in increased risk of maternal mortality, preterm, low birth weight or stillbirth. From 60 controlled trials review, evidence benefits of iron supplementation was on low birth weight risk and maternal at term anemia status, but not on preterm, neonatal death or maternal morbidity and death [16] [17].

At least half of pregnancy anemia is due to iron deficiency and the prevalence of folate deficiency in pregnant is higher among women from low socioeconomic status [1].

In developing countries, to achieve improvement of maternal health (Millennium Development Goal 5) one of the challenges is to address the pregnancy anemia problem both creatively a strategically appropriate actions. Most of the pregnancy anemia risk factors are poverty related and chronic: women socio-demographic factors (age, education level, marital status), less access to antenatal care, obstetrics factors (number of deliveries and pregnancies), household nutritional insecurity. Interventions must be focused on prevention.

The first line facilities of heath system must assure timely routine iron supplementation in antenatal care for healthy pregnant women and real help from care providers to met adequate notional diet (pregnant women need to consume additional iron to prevent iron deficiency). Daily iron and folic acid supplementation in healthy pregnant women is part of the antenatal care as a public health measure to improve pregnancy outcomes, maternal anemia and iron deficiency.

At hospital level, a skilled staff must treat anemia (use of IV or IM iron, blood transfusion if indispensable), including nutritional component and treatment of local prevalent other causes of anemia. At community level: interventions must combine iron food fortification, health and nutrition education, parasitic infection control and sanitation improvement. Community health workers must be trained to advice for adequate nutrition, pregnancy iron supplementation adherence, identifying and immediate referral of pregnancy anemia.

It can be highly benefited to build up iron store at distance of pregnancy by anemia screening on adolescents' girls, cases treatment and iron reach food promoting between these populations).

\section{Conclusion}

Severe anemia during pregnancy results in maternal mortality, preterm, low birth and stillbirth, even between hospitalized women. The challenge is to address the pregnancy anemia problem through creatively and strategi- 
cally appropriate actions. In low income countries, as most of the pregnancy anemia risk factors are chronic poverty related factors, intervention must be focused on prevention including health pregnant women iron supplementation and adequate nutritional diet promoting at both health facilities and community level.

\section{Acknowledgements}

Commission Universitaire pour le Développement (CUD), Belgium, laboratory analysis, medicines for opportunistic diseases.

\section{References}

[1] Karaoglu, L., Pehlivan, E., Egri, M., Deprem, C., Gunes, G., Genc, M.F. and Temel, I. (2010) The Prevalence of Nutritional Anemia in Pregnancy in an East Anatolian Province, Turkey. BMC Public Health, 10, 329. http://www.biomedcentral.com/1471-2458/10/329 http://dx.doi.org/10.1186/1471-2458-10-329

[2] Christensen, R.D. and Ohls, R.K. (2004) Anaemias Unique to Pregnancy and the Perinatal Period. In: Greer, J.P., Foerster, J., Lukens, N.J., Rodgers, G.M., Paraskevas, F. and Glader, B., Wintrobe's Clinical Hematology, Vol. 2, 11th Edition, Lippincott Williams and Wilkins, USA, 1467-1486.

[3] De Benoist, B., McLean, E., Egli, I. and Cogswell, M. (2008) Worldwide Prevalence of Anaemia 1993-2005: WHO Global Database on Anaemia. World Health Organization, Geneva.

[4] World Health Organization (1992) The Prevalence of Anemia in Women: A Tabulation of Available Information. WHO, Geneva.

[5] Curvo, L.G. and Mahomed, K. (2001) Treatment for Iron Deficiency Anemia in Prengnancy. Cochrane Database Systematic Review.

[6] Sifakis, S. and Pharmakides, G. (2000) Anemia in Pregnancy. Annals of the New York Academy of Sciences, 900, 125136. http://dx.doi.org/10.1111/j.1749-6632.2000.tb06223.x

[7] Yip, R. (2000) Significance of an Abnormally Low or High Hemoglobin Concentration during Pregnancy: Special Consideration of Iron Nutrition. American Journal of Clinical Nutrition, 72, 272S-279S.

[8] AbdelAziem, A.A., Duria, A.R., Tajeldin, M.A., Mustafa, I.E. and Adam, I. (2011) Severe Anaemia Is Associated with a Higher Risk for Preeclampsia and Poor Perinatal Outcomes in Kassala Hospital, Eastern Sudan. BMC Research Notes, 4, 311. http://www.biomedcentral.com/1756-0500/4/311 http://dx.doi.org/10.1186/1756-0500-4-311

[9] Allen, L.H. (2000) Anaemia and Iron Deficiency: Effects on Pregnancy Outcome. American Journal of Clinical Nutrition, 71, 1280S-1284S.

[10] Adam, I., Babiker, S., Mohmmed, A., Salih, M., Prins, M. and Zaki, Z. (2007) Low Body Mass Index, Anaemia and Poor Perinatal Outcome in a Rural Hospital in Eastern Sudan. Journal of Tropical Pediatrics, 54, 202-204. http://dx.doi.org/10.1093/tropej/fmm110

[11] Elhassan, E.M., Abbaker, A.O., Haggaz, A.D., Abubaker, M.S. and Adam, I. (2010) Anaemia and Low Birth Weight in Medani, Hospital Sudan. BMC Research Notes, 28, 181. http://dx.doi.org/10.1186/1756-0500-3-181

[12] Haggaz, A.D., Radi, E.A. and Adam, I. (2010) Anaemia and Low Birth Weight in Western Sudan. Transactions of the Royal Society of Tropical Medicine and Hygiene, 104, 234-236. http://dx.doi.org/10.1016/j.trstmh.2009.07.013

[13] Kidanto, H.L., Mogren, I., Lindmark, G., Massawe, S. and Nystrom, L. (2009) Risks for Preterm Delivery and Low Birth Weight Are Independently Increased by Severity of Maternal Anaemia. South African Medical Journal, 99, 98102.

[14] Ali, A.A. and Adam, I. (2011) Anaemia and Stillbirth in Kassala Hospital, Eastern Sudan. Journal of Tropical Pediatrics, 57, 62-64. http://dx.doi.org/10.1093/tropej/fmq029

[15] Riffat, J. and Ayesha, K. (2008) Severe Anemia and Adverse Pregnancy Outcome. Journal of Surgery Pakistan (International), 13, 147.

[16] Peña-Rosas, J.P. and Viteri, F.E. (2009) Effects and Safety of Preventive Oral Iron or Iron + Folic Acid Supplementation for Women during Pregnancy. Cochrane Database of Systematic Reviews, 4, CD004736.

[17] Peña-Rosas, J.P. and Viteri, F.E. (2012) Daily Oral Iron Supplementation during Pregnancy. Cochrane Database of Systematic Reviews, 12, CD004736. 